\title{
Remote Educational Experiment Applied To Electrical Engineering
}

\author{
http://dx.doi.org/10.3991/ijoe.v9i1.2298 \\ J.M.Neto ${ }^{1}$, S. Paladini' ${ }^{2}$, C.E.Pereira ${ }^{2}$, R. Marcelino ${ }^{3}$, V. Gruber ${ }^{3}$, J.B. Silva ${ }^{3}$ \\ ${ }^{1}$ School of Engineering, Department of Electrical Engineering SATC, Criciúma-SC (Brazil) \\ ${ }^{2}$ School of Engineering UFRGS, Federal University of Rio Grande do Sul Porto Alegre-Rs (Brazil) \\ ${ }^{3}$ UFSC, Federal University of Santa Catarina, Ararangua-SC (Brazil)
}

\begin{abstract}
This article presents the development of an architecture for a remote educational experiment concerning the speed control applied to a direct current motor. The proposed architecture is based on the use of an Arduino Uno and Ethernet Shield, whose function is to interface between the experiment and the Internet. The user can access the control experiment through an application developed in Java, which allows the students to choose the model of the controller (P, PI and PID) they want to study, change its parameters and the system response visualization through graphics and webcam. Results show the potential of the application of such architecture to remote experimentation context concerning engineering, mainly to the specific area of control systems.
\end{abstract}

Index Terms—-Remote Experiment; Rotation control.

\section{INTRODUCTION}

During the last decade there was a rapid development of computer networks and the Internet. The WWW (World Wide Web), one of the most popular Internet services, provided the means of publishing and accessing large volumes of information in textual and multimedia formats. Those WWW characteristics were potential to the development of environments for distance education. [1]

Currently educational methods have been changing. Students have found it difficult to adapt to the traditional teaching techniques still used in the classroom. New methods of teaching, called desirable methods, are alternatives that have appeared and showed to be necessary for this new generation of "plugged-in people ". [2]

Nowadays, engineers, technologists and researchers whose necessities, applications and requirements change very quickly, need the flexibility to create their own solutions. That is a reality in the labor market, and even more in the academic environment, where students need freedom to experiment without being afraid of damaging some equipment. However real experiments installed in the educational institutions laboratories are generally expensive, that is, besides the cost of the equipment, the institution needs to pay for the maintenance, installation and possible replacement of materials used in the real experience. And the increase in the number of students demands an increase in the number of laboratories at universities and other educational institutions.

"Educating in an information society means much more than training people to use information and communication technologies: it means investing in building competences large enough to give them an effective role in the production of goods and services, in making decisions based on knowledge, in operating smoothly the new ways and tools at their work, as well as creatively applying new media, whether in simple and routine uses, or in more sophisticated applications. It means training individuals to learn skills so that they can deal positively with the technological base continuous transformation "[3].

The remote experimentation appears as an extremely interesting alternative to the limited availability of university laboratories in Brazil, since it can be accessed at any time and is connected to the worldwide computer network available 24 hours a day, 7 days a week. Due to its access availability, it becomes easy for the user to interact with the virtual practical activity.[7] It usually consists of a set of software and hardware technologies that can take many different configurations depending on the choice of technological resources employed in its implementation.

It is well known that at laboratories it is possible to apply and test theoretical knowledge in practical situations. The teaching of control and automation systems put students in contact with real situations allowing them to make comparisons of classical and modern theory with practice.

Thus, the purpose of this study is the development of a remote experiment focused on the aid of practical activities carried out by the Electrical Engineering and similar courses, relating to the discipline of control systems, in order to assist students in understanding the content taught in classrooms.

In this context, this paper proposes a remote educational experiment of a current motor (DC motor) control speed, which allow the students to interact with the control systems P, PI, PID applied to the rotation control of the remote mode engine.

\section{EXPERIMENT ARCHITECTURE}

Figure 1 shows the basic diagram of the architecture of the remote experiment, where the main features concerning the proposed structure are detailed below.

\section{A. Hardware Implementation}

This block is composed of an Arduino Uno, which has the electronic board based on the chip ATmega328, manufactured by Atmel. It controls the electric motor by reading the cue generator. To carry out the connections of the proposed experiment, the network Internet is used as means of communication between the user and the remote 


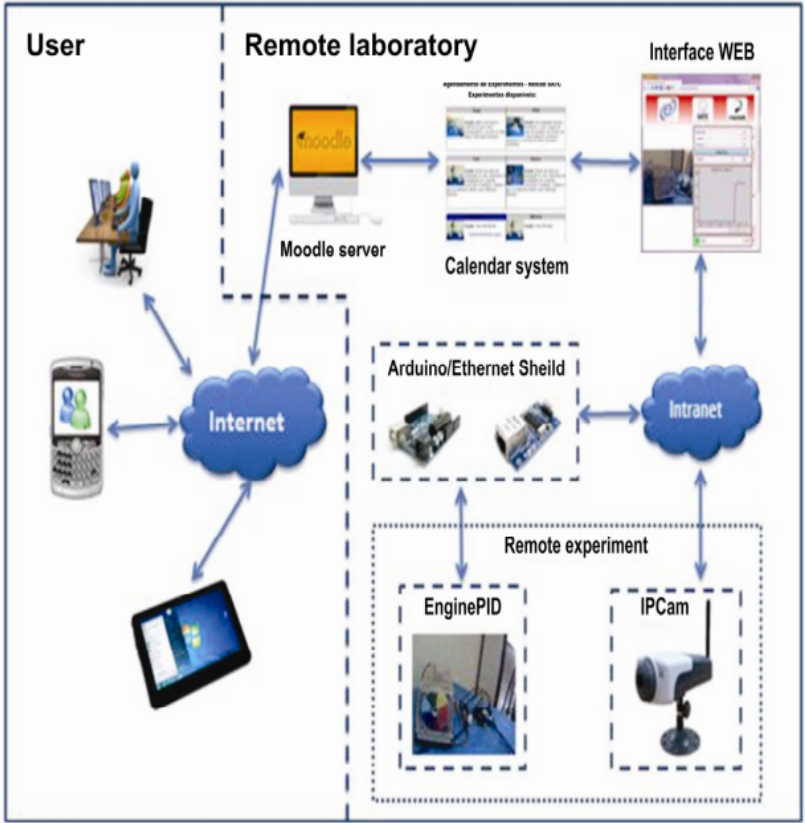

Figure 1. Experiment

TABLE I.

TECHNICAL FEATURES OF ENC28J60. [4]

\begin{tabular}{|c|c|}
\hline MAC & yes \\
\hline PHY & yes \\
\hline TX/RX RAM Buffer (Bytes) & 8192 \\
\hline Interruption pin & 1 \\
\hline LED & 2 \\
\hline Operating voltage $(\mathrm{V})$ & 3.3 \\
\hline Minimum temperature $\left({ }^{\circ} \mathrm{C}\right)$ & -40 \\
\hline Maximum Temperature $\left({ }^{\circ} \mathrm{C}\right)$ & 85 \\
\hline Communication & SPI \\
\hline Pre-programmed MAC address & yes \\
\hline Security mechanisms & Não \\
\hline Ethernet Controller & 10 Base-T \\
\hline
\end{tabular}

educational experiment, being necessary to add the board Arduino to the electronic board Ethernet Shield. The main component of the board is the chip ENC28J60 from Microchip. Table 1 shows details of the chip that represents the main component used in the Shield.

\section{B. Interaction with the Experiment Environment}

The virtual environment was developed in the Java language, this being the place used to create a connection between the user and the remote experiment. The user can interact with the experiment through commands available in the application, which allow the experience to be carried out in the virtual environment, using the Internet as means of communication to receive information from the experiment and control it.

The environment developed in Java was specifically used for the communication with the remote experiment via Internet or local network. This application is a Java applet, and allows it to be hosted on a web page similar to a figure. Thus, this application installs itself in the user's computer, permitting all resources of the application to be used within the browser itself.

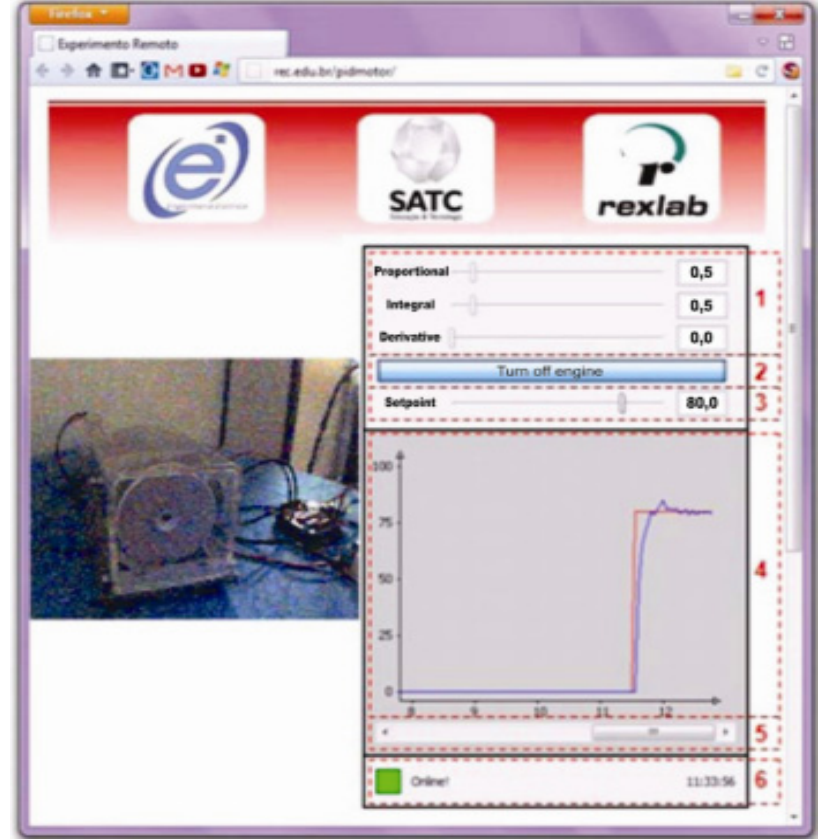

Figure 2. Environment interaction with remote experiment.

TABLE II.

DESCRIPTION OF THE BLOCKS IN THE DEVELOPED ENVIRONMENT

\begin{tabular}{|l|l|l|}
\hline Block & \multicolumn{1}{|c|}{ Name } & \multicolumn{1}{c|}{ Purpose } \\
\hline 1 & $\begin{array}{l}\text { Parameters of PID } \\
\text { controller }\end{array}$ & $\begin{array}{l}\text { Select the values of the parameters of } \\
\text { PID controller (kp, ki and kd) }\end{array}$ \\
\hline 2 & Switch on or off & Turn on or turn off the motor. \\
\hline 3 & $\begin{array}{l}\text { Setpoint } \\
\text { Selection }\end{array}$ & $\begin{array}{l}\text { Choose the desired value of motor } \\
\text { speed }\end{array}$ \\
\hline 4 & Rotation Graphic & $\begin{array}{l}\text { Visualize the values of motor speed } \\
\text { and the setpoint over time. }\end{array}$ \\
\hline 5 & Graphic bar & $\begin{array}{l}\text { Paralyze the graphic to visualize } \\
\text { previous values of speed. }\end{array}$ \\
\hline 6 & $\begin{array}{l}\text { Application } \\
\text { Status }\end{array}$ & $\begin{array}{l}\text { Show the time and messages of the } \\
\text { application operation. }\end{array}$ \\
\hline
\end{tabular}

The applet application developed for interaction with the experiment was inserted in a web page as shown in Figure 2. On this page the DC motor can be visualized, as a webcam is used and it allows the user to visualize the rotation of the motor as required with the application. Moreover, the application allows the motor to be connected and disconnected as well as to modify the parameters of PID controller and to visualize the motor rotation in the graphic.

The web page above shows where the motor can be visualized in order to verify whether the motor really rotates. Beside it, there is the Java applet that permits the user to visualize the motor rotation in the graphic and control the parameters of PID controller. This application has several mechanisms to interact with the user; the functions of each item are depicted in Figure II. Table II shows in detail the purpose of each block in the interaction environment developed for the application.

\section{Software Arduino Implementation}

Among the characteristics that make the software structure allocated in Arduino, two points are highlighted: 
1. The control structure used was the PID (Proportional + Integral + Derivative) as a base for software development. This type of controller was initially chosen, because it is generally applied to most of the control systems of continuous processes, proving its usefulness by providing a generally satisfactory control.

The connection among the proportional, integral and derivative actions result in the PID controller, which can be found in various formats. Among the existing formats, the one chosen to be implemented in the experiment was parallel PID, since it is the most common among industrial controllers. Figure 3 shows the block diagram of a closed loop control system using PID controller.

The figure above shows the PID controller block diagram, which has an adder that integrates the actions of controllers: proportional, integral and derivative actions, resulting in the PID controller in parallel. The controller equation is shown in Equation 1.

$$
u(t)=k_{p} e(t)+K_{i} \int_{0}^{t} e(\tau) d \tau+K_{d} \frac{d e(t)}{d t}
$$

Using the above equation of the PID controller in time domain it is possible to develop an equation of a digital PID controller in order to use it on the Arduino. To approximate the equation 1 , a $\mathrm{T}$ period sampling rate was used, thus the integral action is close to the sum of all values of the sampled error multiplied by the period, and the derivative action multiplied by the difference between the current and previous error divided by the period. Equation (2) expresses the structure of the PID controller used.

$$
P I D=k_{p} e(t)+K_{i} T \sum_{i=0}^{t} e(i)+K_{d} \frac{e(t)-e(t-1)}{T}
$$

Through equation 2 the subroutine digital PID inserted into Arduino was developed, as shown in Figure 4, being the parameters of PID controller, the proportional, integral and derivative gain, subject to be modified by the user through the graphical interphase.

2. To realize the communication internet to Java application, through which the user can access the educational experiment, it was necessary to implement the TCP / IP protocol and use the Socket Access Method. Thus when the Arduino receives or sends data packets it uses the functions detailed in Figure 5, which make part of the Ethernet Shield library.

\section{VALIDATION OF RESULTS}

Mathematical modeling of a dynamic process can be defined as the determination of a set of equations that represent it under certain conditions. [5] It is noteworthy that a physical system can be represented in several different ways, so there may be many mathematical models which represent the behavior of a given system. Therefore, in this study a simplified description was chosen, concerning the simplicity of the model and its fidelity in representation. For this process, the model was obtained from the measurements associated with the experiment and collected from an experimental realization

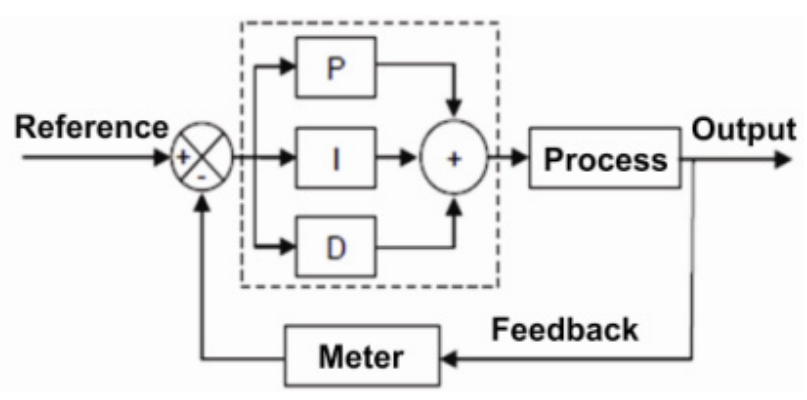

Figure 3. Block diagram of a PID controller.

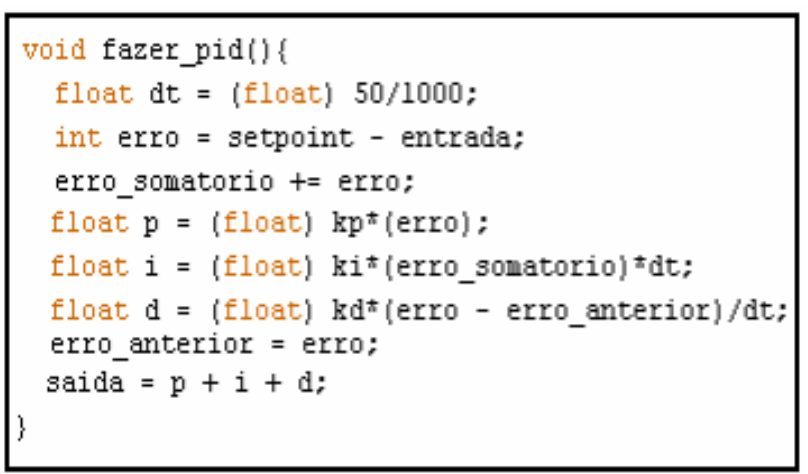

Figure 4. Subroutine developed PID

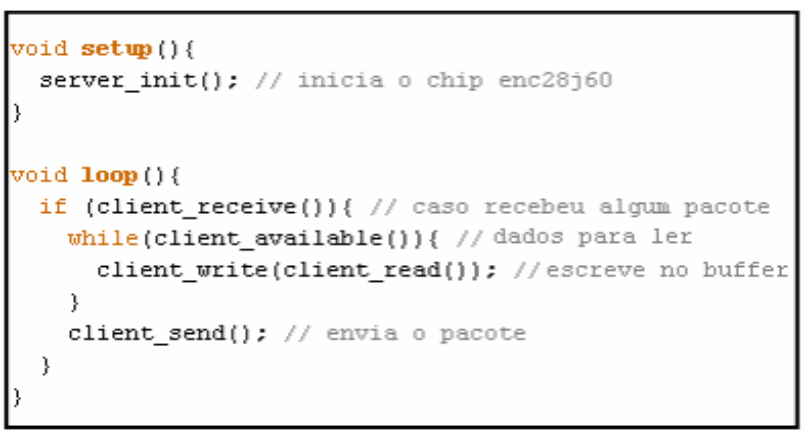

Figure 5. Structure of sending and receiving data via Internet.

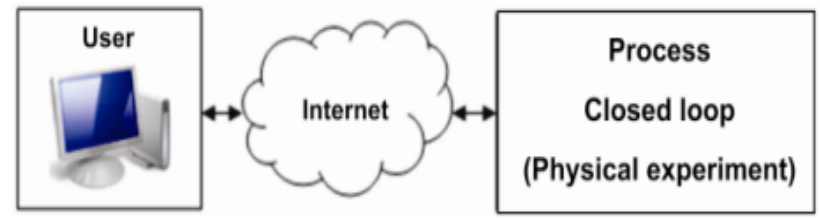

Figure 6. Structure used in the identification of dynamic

through the learning environment described above. The study used the identification by close-loop step response tests, as shown in Figure 6.

\section{A. Obtaining a Mathematical Model}

According to Coelho and Coelho (2004), based on the temporal response it is possible to measure points to aid the application of different methods to identify the mathematical equations representing the systems. In literature there are several methods based on the step process response to identify the gain parameters $(\mathrm{K})$, the transport delay $(\tau)$ and the time constant $(\theta)$. [6]

The mathematical model related to the DC motor speed, was obtained from step tests type by applying the method Hägglund to obtain the transfer function of the first order 
system represented by F1 (s), and the method Mollenkamp for the second order system, identified by F2 (s). These methods lead to the identification of process characteristics such as the time and delay constants gain value, which are essential for the control system building. These characteristics are important to validate the possible responses to be generated by the proposed educational experiment. Through both methods, the transfer functions shown in equation (3) and equation (4) were determined for later comparison of responses between the simulations in Matlab software and the actual performance of the implemented system.

$$
\begin{array}{r}
F 1(s)=\frac{1,25}{0,2 s+1}(3) \\
F 2(s)=\frac{1,25}{0,00216 s^{2}+0,1753 s+1}
\end{array}
$$

To compare the real system response to the proposed model Table III was structured in order to observe the behavior of systems with the possible configurations of controllers and values of $\mathrm{Ki}, \mathrm{Kp}$ and $\mathrm{Kd}$. Moreover, the convergence of the output signal to the desired value was verified, as well as the similarity between them.

The simulations to be presented were developed with the support of MATLAB software being presented simulations F1 (s) and F2 (s) applied to the possible configurations of controllers (P, PI and PID).

Figure 7 shows the simulated functions F1 (s), F2 (s) being implemented in a proportional controller setpoint value equal to $60 \%$ of the maximum and $\mathrm{Kp}$ equal 1 , identified by the red and green, respectively. Because it is a proportional controller only, does not nullify the error in steady state, which keeps the dynamics described in control theory. That is, has a visible difference between the value of engine speed and the setpoint.

Figure 8 shows the results of the experiment with the same parameters assigned to the previous simulation.

From Figure 9 shows the graph regarding the performance of the experiment remote controller when submitted to a proportional and integral (PI) and Kp value equal to and ki equals 5 to 0.5 .

It is notable that the addition of the integral component of the control system eliminates the error in steady state. However when subjected to a high gain integral constant results in increasing the signal and on a larger settling time of the system, and these features also perceived in the simulations in Matlab.

TABLE III.

CONTROLLERS AND GAIN PARAMETERS

\begin{tabular}{|l|c|c|c|c|c|c|}
\hline Set point & \multicolumn{3}{|c|}{$\mathbf{6 0 \%}$} & \multicolumn{3}{c|}{$\mathbf{8 0 \%}$} \\
\hline Controllers & $\mathrm{Kp}$ & $\mathrm{Ki}$ & $\mathrm{Kd}$ & $\mathrm{Kp}$ & $\mathrm{Ki}$ & $\mathrm{Kd}$ \\
\hline \multirow{3}{*}{$\mathrm{P}$} & 1.0 & - & - & 1.0 & - & - \\
\cline { 2 - 7 } & 5.0 & - & - & 5.0 & - & - \\
\hline \multirow{3}{*}{ PI } & 5.0 & 0.5 & - & 5.0 & 0.5 & - \\
\cline { 2 - 7 } & 5.0 & 2.0 & - & 5.0 & 2.0 & - \\
\hline \multirow{4}{*}{ PID } & 5.0 & 0.5 & 0.5 & 5.0 & 0.5 & 0.5 \\
\cline { 2 - 7 } & 5.0 & 2.0 & 0.5 & 5.0 & 2.0 & 0.5 \\
\cline { 2 - 7 } & 5.0 & 0.5 & 2.0 & 5.0 & 0.5 & 2.0 \\
\cline { 2 - 7 } & 5.0 & 2.0 & 2.0 & 5.0 & 2.0 & 2.0 \\
\hline
\end{tabular}

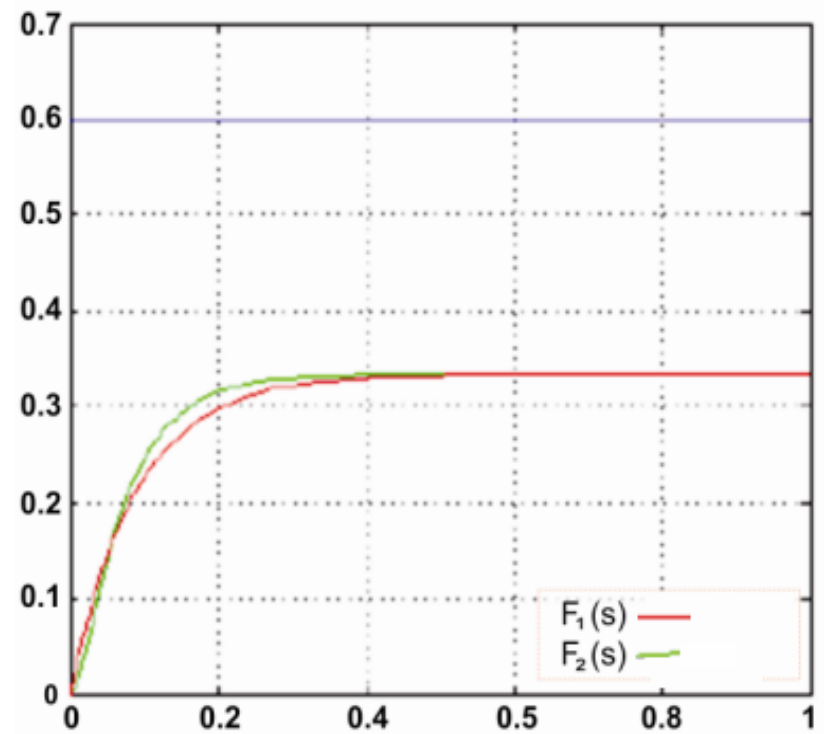

Figure 7. Simulation of the Response submitted Controller P

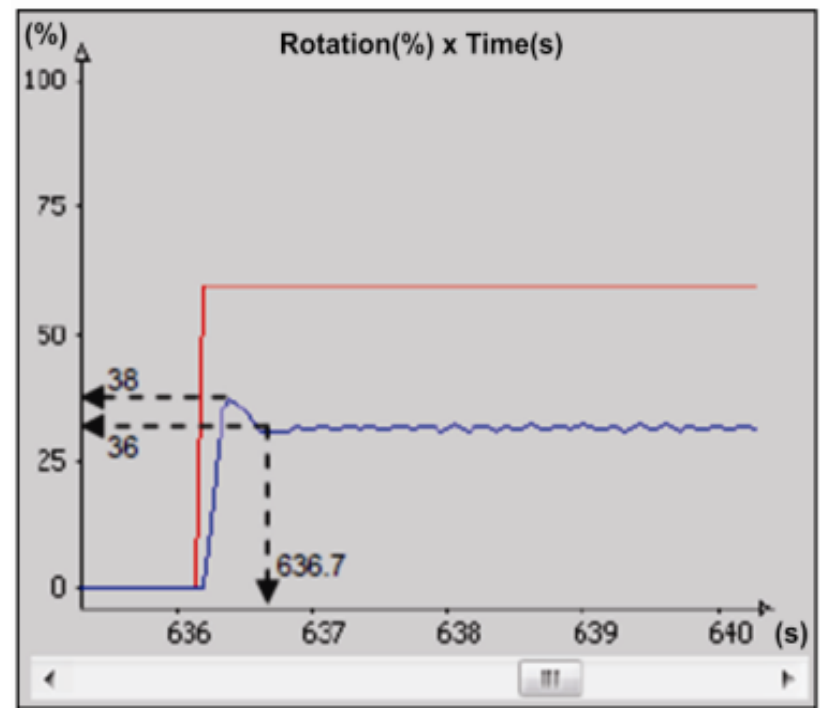

Figure 8. Response of experiment submitted to the controller P

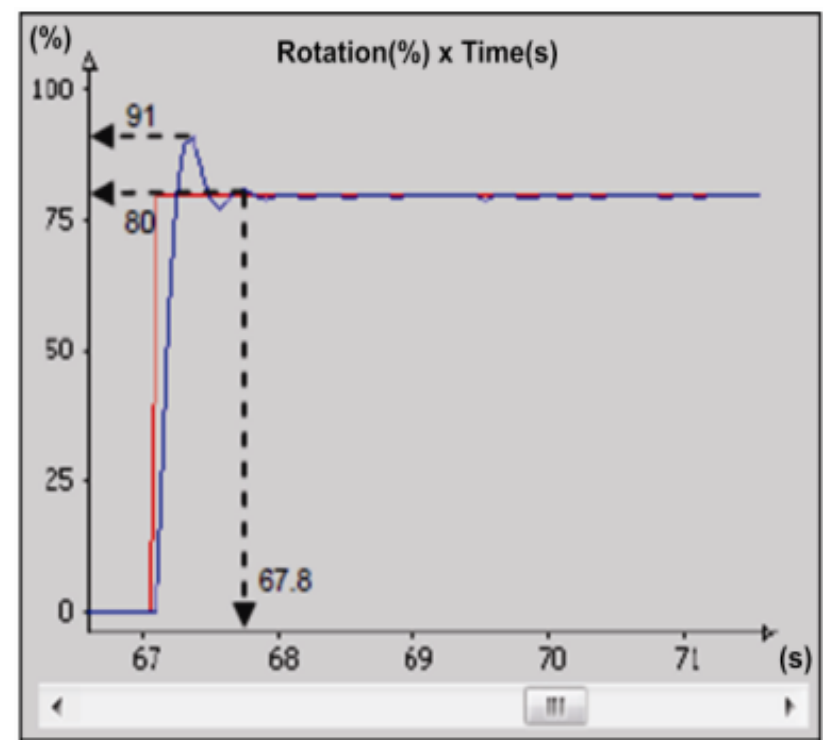

Figure 9. Response of experiment submitted to the controller PI 


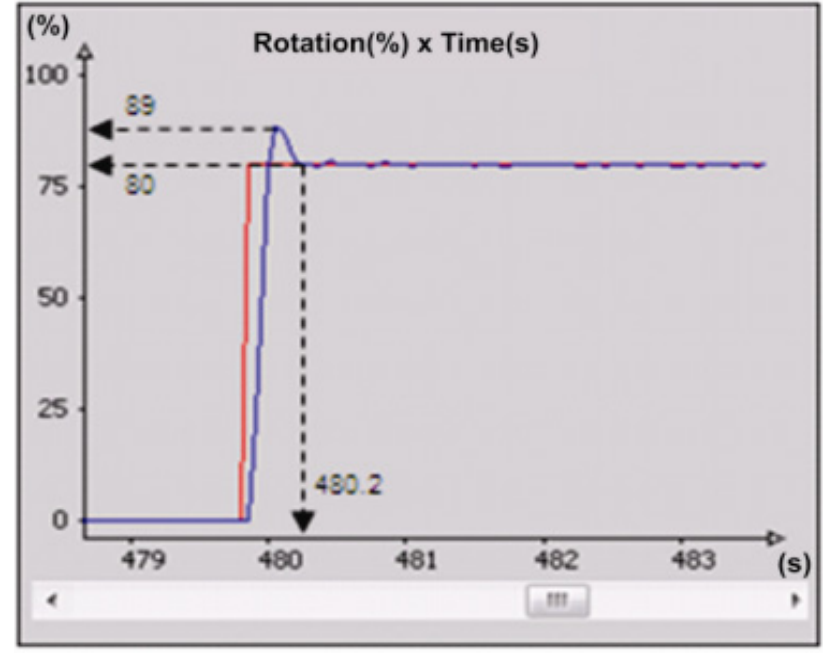

Figure 10. Response of experiment submitted to the controller PID

TABLE IV.

QUIZ QUESTIONS AND ANSWERS

\begin{tabular}{|c|c|c|c|}
\hline \multicolumn{4}{|c|}{$\begin{array}{l}\text { Experiment contributed to better understanding the concepts } \\
\text { developed in the discipline of control systems? }\end{array}$} \\
\hline Excellent & Good & Regular & Bad \\
\hline $43 \%$ & $36 \%$ & $11 \%$ & $10 \%$ \\
\hline \multicolumn{4}{|c|}{$\begin{array}{l}\text { What is your impression about developing experiments remote } \\
\text { related to control systems? }\end{array}$} \\
\hline Excellent & Good & Regular & Bad \\
\hline $40 \%$ & $38 \%$ & $14 \%$ & $8 \%$ \\
\hline \multicolumn{4}{|c|}{$\begin{array}{l}\text { In your opinion greater learning control systems in the } \\
\text { development of activities linked to experiments remote or } \\
\text { simulations? }\end{array}$} \\
\hline Simulation & $\begin{array}{l}\text { Real experi- } \\
\quad \text { ments }\end{array}$ & Both & $\begin{array}{l}\text { Combination of } \\
\text { both }\end{array}$ \\
\hline $5 \%$ & $27 \%$ & $44 \%$ & $24 \%$ \\
\hline
\end{tabular}

Figure 10 shows the results of an implementation of the PID controller used for the experiment remote setpoint is equal to $60 \%$ of the maximum value, equal to $5 \mathrm{Kp}, \mathrm{Ki}$ egual to 0.5 , and $\mathrm{Kd}$ equal to 2 . Become visible controller performance in reduce the oscillation overshoot and undershoot of system system.

\section{FINAL CONSIDERATIONS}

The PID controller used in the experiment under study resulted in adequate control of motor rotation, the earnings used as the response of the system satisfies the expected. The simulation made from the transfer functions obtained by graphical analysis of the convergence was observed responses of the physical system implemented with the theoretical control systems.

A test was conducted in the regions near Criciúma, Santa Catarina, in order to check the instability and connection reliability, and is proved effective even for low band internet as $256 \mathrm{kbps}$. In a few moments indicated the system fails to connect, but it lasted at most a few units of seconds, not affecting the performance of the experiment, because the data are not lost, and by the fact that the system not to operate because of these failures .

Currently, the class of students are using blended learning scenario proposed in the discipline of control theory (graduate course in electrical engineering). A personalized quiz is designed to "evaluate" the qualities and faults of the system, the most significant questions of this test and the answers are shown in Table IV.

\section{REFERENCES}

[1] CHELLA, Marco Túlio. Arquitetura para Laboratório de Acesso Remoto com Aplicações Educacionais. 2006. 170 f. Tese (Tese) Departamento de Engenharia Elétrica e da Computação - Feec, Universidade Estadual de Campinas - Unicamp, Campinas, 2006.

[2] MARCELINO, R. ; Silva, Juarez Bento da ; Alves, Gustavo Ribeiro ; Shaeffer, Lírio . Extended Immersive Learning Environment: A Hybrid Remote/Virtual Laboratory. International journal of online engineering, v. 6, p. 1-6, 2010

[3] SOCINFO 2000. Sociedade da Informação no Brasil - Livro Verde. Ministério da Ciência e Tecnologia. Brasília. DF. Setembro 2000.

[4] Arduino Ethernet Shield. Disponível em:

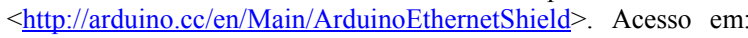
15 nov. 2011.

[5] LEAL, A.B.; 1996. Controle Multivariável Robusto de um Sistema Térmico : Comparaçãoentre Técnicas de Controle. Florianópolis. Dissertação (Mestrado em Engenharia Elétrica) - Centro Tecnológico, Universidade Federal de Santa Catarina.

[6] Coelho, Antonio Augusto Rodrigues; Coelho, Leandro Dos Santos, 2004. "Identificação de Sistemas Dinâmicos Lineares", Editora UFSC, Santa Catarina.

[7] Silva, Juarez B. ; Gruber, Vilson ; Marcelino, Roderval . New Technologies for Information and Communication, PWM Remote Experimenting and $3 \mathrm{G}$ Networks as Teaching Support. International Journal of Engineering Pedagogy (iJEP), v. 2, p. 17$22,2012$.

\section{AUTHORS}

J. M. Neto is a teacher of Department of Electrical Engineering SATC, Street Pascoal Meller, 73. CriciúmaSC (Brazil) (joao.neto@satc.edu.br).

S. Paladini, is a researcher at Federal University of Rio Grande do Sul (UFRGS), Porto Alegre, Brazil. (suenoni.paladini@ufrgs.br).

R. Marcelino, is a researcher at Federal University de Santa Catarina (UFSC), Araranguá, Brazil (roderval.marcleino@ufsc.br).

C. E. Pereira, teacher Department of Electrical Engineering Federal University of Rio Grande do Sul UFRGS Porto Alegre, RS, Brazil (cpereira@ece.ufrgs.br.)

V. Gruber, is a researcher at Universidade Federal de Santa Catarina (UFSC), Araranguá, Brazil. (e-mail: vilsongruber@msn.com).

J.B. Silva, is a researcher at Universidade Federal de Santa Catarina(UFSC), Araranguá, Brazil. (e-mail: juarezbs@mail.com).

Received 2 October 2012. Published as resubmitted by the authors 24 January 2013. 